\title{
BMJ Open Association between participation in the government subsidy programme for domestic travel and symptoms indicative of COVID-19 infection in Japan: cross-sectional study
}

\author{
Atsushi Miyawaki (D) , ${ }^{1}$ Takahiro Tabuchi (D) , ${ }^{2}$ Yasutake Tomata, ${ }^{3}$ \\ Yusuke Tsugawa (D) ${ }^{4,5}$
}

To cite: Miyawaki A, Tabuchi T, Tomata Y, et al. Association between participation in the government subsidy programme for domestic travel and symptoms indicative of COVID-19 infection in Japan: cross-sectional study. BMJ Open 2021;11:e049069. doi:10.1136/ bmjopen-2021-049069

- Prepublication history and additional supplemental material for this paper are available online. To view these files, please visit the journal online (http://dx.doi.org/10.1136/ bmjopen-2021-049069).

Received 16 January 2021 Revised 29 March 2021 Accepted 30 March 2021

Check for updates

(C) Author(s) (or their employer(s)) 2021. Re-use permitted under CC BY-NC. No commercial re-use. See rights and permissions. Published by BMJ.

For numbered affiliations see end of article.

Correspondence to

Dr Atsushi Miyawaki;

amiyawaki-tky@umin.ac.jp

\section{ABSTRACT}

Objective To investigate the association between participation in government subsidies for domestic travel (subsidise up to $50 \%$ of all travel expenses) introduced nationally in Japan on 22 July 2020 and the incidence of symptoms indicative of COVID-19 infections.

Design Cross-sectional analysis of nationally representative survey data.

Setting Internet survey conducted between 25 August and 30 September 2020 in Japan. Sampling weights were used to calculate national estimates.

Participants 25482 survey respondents (50.3\% (12809) women; mean (SD) age, 48.8 (17.4) years).

Main outcome measures Incidence rate of five symptoms indicative of the COVID-19 infection (high fever, sore throat, cough, headache, and smell and taste disorder) within the past month of the survey, after adjustment for characteristics of individuals and prefecture fixed effects (effectively comparing individuals living in the same prefecture)

Results At the time of the survey, 3289 (12.9\%) participated in the subsidy programme. After adjusting for potential confounders, we found that participants in the subsidy programme exhibited higher incidence of high fever (adjusted rate, $4.7 \%$ for participants vs $3.7 \%$ for non-participants; adjusted OR (aOR) $1.83 ; 95 \% \mathrm{Cl} 1.34$ to 2.48 ; $p<0.001$ ), sore throat (19.8\% vs $11.3 \%$; aOR 2.09 ; $95 \% \mathrm{Cl} 1.37$ to $3.19 ; p=0.002)$, cough $(19.0 \%$ vs $11.3 \%$; a0R 1.96; $95 \% \mathrm{Cl} 1.26$ to $3.01 ; \mathrm{p}=0.008)$, headache (29.2\% vs $25.5 \%$; aOR $1.24 ; 95 \% \mathrm{Cl} 1.08$ to 1.44 ; $\mathrm{p}=0.006)$ and smell and taste disorder $(2.6 \%$ vs $1.8 \%$; aOR 1.98; $95 \% \mathrm{Cl} 1.15$ to $3.40 ; p=0.01$ ) compared with non-participants. These findings remained qualitatively unaffected by additional adjustment for the use of 17 preventative measures (eg, social distancing, wearing masks and handwashing) and fear against the COVID-19 infection.

Conclusions The participation of the government subsidy programme for domestic travel was associated with a higher probability of exhibiting symptoms indicative of the COVID-19 infection.
Strengths and limitations of this study

- This is the first study that investigates the association between the participation in the government subsidy programme for domestic travel and the incidence of symptoms indicative of the COVID-19 infection ('COVID-19 like symptoms') using data from a large nationwide internet survey conducted in Japan.

- We used a unique setting in which a large nationwide government subsidy for travel was initiated before the COVID-19 pandemic was fully under control.

- Given the cross-sectional design of our study, we could not identify the temporal relationship between the subsidy programme and the incidence of COVID-19 like symptoms.

- Our findings may be affected by the possibility that individuals who presented with COVID-19 like symptoms might recall and report using the subsidy programme for domestic travel (recall bias).

\section{INTRODUCTION}

As of the end of December 2020, 81 million people have been infected by the COVID-19, and 1.8 million have died from this infection. ${ }^{1}$ To tackle this unprecedented pandemic, many countries have implemented public health measures-also known as nonpharmaceutical interventions (NPIs)-to control the spread of the virus, including lockdowns, movement restrictions, quarantines and border controls. ${ }^{2}$ Given that the number of infections and deaths due to COVID-19 has resurged this winter, these NPIs are likely to be implemented intermittently, ${ }^{3}$ until effective vaccines are developed and become widely available. While these NPIs have been shown to be effective in reducing the spread of COVID-19 infections, ${ }^{24}$ they have a substantial negative impact on economies. ${ }^{5}$ 
As a countermeasure against the economic downturns due to the NPIs, many countries have introduced, or are actively considering, financial incentives such as government subsidies to engage in economic activities, such as using restaurants or travelling domestically. ${ }^{6-10}$

Evidence is limited as to whether the government interventions to financially incentivise economic activities, such as using restaurants or travelling, impact the COVID-19 infection rate. For example, the UK implemented the 'Eat out to Help out' campaign, in which the government subsidised up to $50 \%$ of the expenses of food and non-alcoholic drinks for immediate consumption at restaurants using a budget of around $£ 500$ million throughout August 2020. ${ }^{9}$ A study using ecological data on COVID-19 infections by region suggested that regions that implemented this campaign experienced $8-17$ percentage points higher number of COVID-19 clusters. ${ }^{11}$ However, an ecological association does not imply that the same association would be observed at the individual level (the 'ecological fallacy'), and therefore, it remains unknown as to whether this policy actually led to an increased number of individuals infected by COVID-19. Indeed, to our knowledge, no study to date has evaluated the impact of such an economic policy on the risk of contracting the COVID-19 infection using individual-level data. Moreover, it remains unknown as to how similar policies implemented in other countries that incentivise economic activities (eg, eating out and travel) affected the COVID-19 pandemic.

Japan implemented a large-scale, nationwide government subsidy programme for domestic travel (called the 'Go-To Travel' Campaign) ${ }^{8}$ on 22 July 2020 (announced on 10 July 2020) to revive the travel industry, which has been hit hard by a substantial decrease in the number of foreign tourists visiting Japan. This programme incentivises people to travel domestically by subsidising up to $50 \%$ of transportation and accommodation expenses for travellers. As of the end of October 2020, more than 200 billion Japanese yen (approximately US $\$ 2$ billion), using an exchange rate of 100 Japanese yen per US\$) have been used to subsidise a total of 40 million people who travelled domestically. ${ }^{12}$ However, as the number of COVID-19 infected cases has resurged, the Japanese government faced fierce criticisms from those speculating that increased mobility and human interactions due to the 'Go-To Travel' programme might be causing the increase in the number of COVID-19 infections. ${ }^{13}$ As a result, the Japanese government has suspended this subsidy programme since 28 December 2020 but is considering resuming it (as of March 2021) ${ }^{14}$ Yet, empirical evidence is lacking as to whether the introduction of this programme is associated with an increased risk of contracting the COVID-19 infection. Japan's experience from this social experiment provides a unique opportunity to understand the impact of government subsidies for travel on the spread of COVID-19 infections.

In this context, using data from a large internet survey conducted in Japan between 25 August and 30 September
2020, we examined whether individuals who used subsidies experienced a higher incidence of symptoms indicative of the COVID-19 infection (COVID-19 like symptoms).

\section{METHODS}

\section{Study design, setting and data sources}

We analysed data from the Japan 'COVID-19 and Society' Internet Survey (JACSIS) study, a cross-sectional, web-based, self-reported questionnaire survey administered by a large internet research agency (Rakuten Insight, Inc). Rakuten Insight, Inc is a research agency with a survey panel of approximately 2.2 million registered individuals in 2019. For the purpose of this study, we collaborated with this company to reach out to registered individuals in a way that could be analysed as a nationally representative sample. ${ }^{15}$ This internet research agency has been used in previous studies, ${ }^{1617}$ and the registered individuals are assured through annual updates of demographic information and the exclusion of individuals with concerns about incorrect information. This study collected a wide range of sociodemographic, lifestyle and health measures from individuals aged 15-79 years. The questionnaires were distributed to 224389 individuals selected by gender, age and prefecture category using simple random sampling and covering all 47 prefectures (first-tier administrative districts in Japan). Individuals who consented to participate in the survey accessed the designated website and responded to questionnaires. They also had the option not to respond or to discontinue at any point in the survey; in such cases, they were regarded as not having consented to participate in the survey and were not counted as respondents. Questionnaires were distributed from 25 August 2020 to 30 September 2020, when the target number of respondents for each gender, age and prefecture category were met. These target numbers had been determined in advance according to the population distribution in 2019 as 28000 respondents and a response rate of $12.5 \%$ (28 000/224 389). Although there was no missing value due to the survey design described previously (if any item was not responded, the survey could not be completed), there was still a possibility of unnatural or inconsistent responses. We excluded 2518 individuals showing unnatural or inconsistent responses using the algorithm we developed (see online supplemental method A1 for details). ${ }^{18}$ The final sample size was 25482 respondents (91.0\% of the total survey respondents).

\section{Exposure variables}

The primary exposure variable was participating at least once in travel or accommodation funded by the subsidy programme for domestic travel, which was announced on 10 July 2020 and implemented on 22 July 2020.

\section{Outcome variables}

Our outcome variable was the incidence of five selfreported COVID-19-like symptoms (high fever, sore 
throat, cough, headache, and smell and taste disorder) within the past month of the survey. These symptoms are reported to have high sensitivity $(50 \%$ for high fever and $70 \%$ for cough) or specificity $(70 \%$ for sore throat, $80 \%$ for headache and $90 \%$ or higher for smell and taste disorder).${ }^{19}$ Self-reported COVID-19 like symptoms have been reported as a useful measure to monitor the spread of COVID-19 infections. ${ }^{2021}$

\section{Adjustment variables}

We adjusted for the respondents' demographics, ${ }^{22}$ socioeconomic status (SES), ${ }^{23}$ health-related characteristics, ${ }^{22}$ use of preventive measures (see further for details), perceived fear against the COVID-19 infection and prefecture fixed effects. The demographics included age (categorised as 15-19, 20-29, .., 70-79) and gender. The SES included academic attainment (graduated from college or institutions of higher education vs high school or lower institutions), income level (categorised using the tertiles of household equivalent income ('low'=less than 2.5 million Japanese yen, 'medium' $=2.5-4.3$ million Japanese yen and 'high'=more than 4.3 million Japanese yen) and an indicator for those who refused to respond to this question), household size (number of household members: 1, 2, 3, 4 and 5+), employment status (employer, self-employed, employee and unemployed), marital status (married, never married, widowed and separated) and receipt of lay-off or unemployment benefits after April 2020. The household equivalised income was calculated as the gross (pretax) income in 2019, divided by the square root of the number of household members. Healthrelated characteristics included smoking status (never, ever and current smokers), walking disability (whether the person is experiencing difficulties in walking) and eight comorbidities (overweight (body mass index $\geq 25 \mathrm{~kg} / \mathrm{m}^{2}$ ) and seven self-reported medical histories of hypertension, diabetes, asthma, coronary disease, stroke, chronic obstructive pulmonary disease and cancer). Body mass index was calculated by dividing self-reported body weight by self-reported body height squared $\left(\mathrm{m}^{2}\right)$.

As for preventive measures, the personal preventive actions included indicators of whether the respondent implemented each of the nine personal protective measures ( $1=$ always/sometimes, $0=$ rarely/never) recommended by the $\mathrm{WHO}^{24}$ : social distancing, wearing masks, avoiding closed spaces, avoiding crowded spaces, avoiding close contact settings, handwashing, avoiding touching face, respiratory hygiene and surface disinfection. High-risk behaviour patterns included indicators of whether the respondent visited restaurants, bars/nightclubs, karaoke bars, fitness clubs and brothels during the state of emergency in April-May (1=frequently, occasionally and at least once, and $0=$ never).$^{25}$ Proxy variables of other preventive measures included indicators of the use of the contact-tracing application, ${ }^{26}$ support for stay-athome requests $(1=$ very/somewhat, $0=$ slightly/never) and influenza vaccination in the last season (as a proxy for the likelihood of receiving the COVID-19 vaccination when it becomes available).

The perceived fear against the COVID-19 infection was adjusted for to test whether the difference in the risk preference between participants and non-participants could explain the differences in the incidence of the COVID-19 like symptoms. It was measured on a five-point scale of 'not afraid at all $(0 \%$ if I were to rate the level of fear between $0 \%$ and 100\%)', 'not afraid (25\%)', 'neutral (50\%)', 'somewhat afraid (75\%)' and 'very afraid (100\%)' to the question 'Are you afraid of the COVID-19 infection?'.

Prefecture fixed effects are indicator variables for each prefecture, which account for both measured and unmeasured characteristics of the prefecture (Japan consists of 47 prefectures, which are the country's first jurisdiction and administrative division levels). The inclusion of prefecture fixed effects allows us to effectively compare participants versus non-participants of the programme living in the same prefecture.

\section{Statistical analysis}

First, we compared the demographics, SES, healthrelated characteristics, preventive measures and fear against the COVID-19 infection employed by participants in the subsidy programme for domestic travel versus nonparticipants. To account for the possibility that those who participated and responded to the internet-based survey may differ from the general population (eg, a younger population may be more likely to participate and respond to an internet-based survey), we applied an inverse probability weighting (IPW) approach throughout the analyses. ${ }^{27}$ The weights (the inverse of propensity scores representing the estimated probability of participating in the survey) were calculated by fitting a logistic regression model using demographics, SES and health-related characteristics to adjust for the difference in respondents between the current internet survey and a widely used nationwide representative survey (ie, the 2016 Comprehensive Survey of Living Conditions ${ }^{28}{ }^{29}$ ) (see online supplemental method A2 for details).

Second, we examined the association between participation in the subsidy programme for domestic travel and the incidence rates of COVID-19 like symptoms. For each outcome, we constructed two regression models to control for potential confounders. Model 1 adjusted for the respondents' sociodemographic characteristics, health-related characteristics and prefecture fixed effects. Model 2 adjusted for all the variables included in model 1 plus the use of preventive measures and fear against the COVID-19 infection to investigate whether these factors could explain the observed differences in the incidence of symptoms related to COVID-19. We used weighted multivariable logistic regression models, with SEs clustered at the prefecture level, to account for the potential correlation of respondents within the same prefecture. To calculate risk-adjusted incidence rates of COVID-19 like symptoms, we used marginal standardisation (also known as predictive margins or margins of response). ${ }^{30}$ For each 
respondent, we calculated predicted probabilities of the incidence of COVID-19 like symptoms with participation in the subsidy programme fixed at each category and then averaged over the distribution of covariates in our sample.

To adjust for multiple comparisons of having five outcome variables using the Holm method, ${ }^{31}$ which sequentially compares the $i$-th smallest $\mathrm{p}$ value (for $i=1$, $\ldots, 5)$ among the five original $p$ values with progressively less restrictive alpha levels $(=0.05 /(5-i+1))$. To make the interpretation easier, we calculated the adjusted $p$ value by multiplying the unadjusted $\mathrm{p}$ values by $(5-i+1)$ times and considered the adjusted $\mathrm{p}$ value $<0.05$ to be statistically significant. ${ }^{32}$

\section{Sensitivity analysis}

First, travellers to and from Tokyo were ineligible for the subsidy programme until 15 September, due to a large number of COVID-19 cases in Tokyo. ${ }^{8}$ To assess whether our findings were sensitive to the inclusion of Tokyo residents (we included these individuals in our main analyses as they could still participate in the subsidy programme if their companion lived in prefectures other than Tokyo), we reanalysed the data after excluding those respondents living in Tokyo prefecture. Second, we repeated the analyses without using IPW to examine how the use of this approach affected our findings. Third, it is possible that we were comparing individuals who were more versus less likely to travel regardless of the existence of the government subsidy programme for travel. To test this hypothesis, we reanalysed the data restricting to individuals who did not eliminate the possibility of travelling in the past month (excluded individuals who reported that they had avoided any travels in the past month to the question 'Have you avoided travels in the past onemonth?'). Fourth, to test whether the impact of the subsidy programme varied by respondents' characteristics, we conducted stratified analyses by age (15-64 years and 65-79 years), the presence of comorbidities (no comorbidities vs having at least one comorbidity) and gender. Finally, we ran separate analyses for five regions to ascertain whether the relationship between the subsidy programme participation and COVID-19 like symptoms varied regionally.

All analyses were conducted using Stata V.15 (StataCorp LLC, College Station, Texas, USA).

\section{Patient and public involvement}

No respondents were involved in setting the research question or the outcome measures, nor were they involved in the design, implementation and interpretation of the study. All respondents gave informed consent to enrol in the study.

\section{RESULTS}

Characteristics of respondents

Of the 25482 respondents, 3289 (12.9\%) had participated in the subsidy programme for domestic travel at the time of the survey. Participants in the subsidy programme were younger, had higher education and income levels and were more likely to be overweight (table 1). We found no systemic patterns regarding the implementation of preventive actions recommended by WHO (table 2). Notably, participants in the subsidy programme were more likely than non-participants to engage in risky behaviour patterns (visiting restaurants, bars/nightclubs, karaoke bars or fitness clubs at least once) during the state of emergency. As for other preventive measures, participants in the subsidy programme were more likely to use the contact-tracing application and to have received the influenza vaccine in the prior year.

\section{Participation in the subsidy programme for domestic travel} and COVID-19 like symptoms

After adjusting for demographics, SES, health-related characteristics and indicators of prefectures (model 1 in table 3), we found that the adjusted incidence rates of COVID-19 like symptoms were higher for subsidy programme participants compared with non-participants for high fever (adjusted rate, 4.7\% for participants vs 3.7\% for non-participants; adjusted OR (aOR) 1.83 ; 95\% CI 1.34 to 2.48 ; $\mathrm{p}<0.001)$, sore throat $(19.8 \%$ vs $11.3 \%$; aOR 2.09; $95 \%$ CI 1.37 to $3.19 ; \mathrm{p}=0.002)$, cough $(19.0 \%$ vs $11.3 \%$; aOR 1.96 ; $95 \%$ CI 1.26 to $3.01 ; \mathrm{p}=0.008$ ), headache $(29.2 \%$ vs $25.5 \%$; aOR $1.24 ; 95 \%$ CI 1.08 to 1.44 ; $\mathrm{p}=0.006)$ and smell and taste disorder $(2.6 \%$ vs $1.8 \%$; aOR $1.98 ; 95 \%$ CI 1.15 to $3.40 ; \mathrm{p}=0.01$ ). These findings remained largely unchanged after additional adjustments for the use of preventive measures and fear against the COVID-19 infection in model 2; the adjusted incidence rates of COVID-19 like symptoms were higher for subsidy programme participants compared with non-participants for high fever $(4.4 \%$ vs $3.7 \%$; aOR 1.56 ; $95 \%$ CI 1.09 to $2.23 ; \mathrm{p}=0.04)$, sore throat $(18.2 \%$ vs $11.6 \%$; aOR 1.84 ; $95 \%$ CI 1.35 to $2.52 ; \mathrm{p}<0.001)$, cough $(17.1 \%$ vs $11.5 \%$; aOR $1.66 ; 95 \%$ CI 1.21 to $2.26 ; \mathrm{p}=0.006)$, headache (28.2\% vs $25.7 \%$; aOR 1.17 ; $95 \%$ CI 1.02 to $1.34 ; \mathrm{p}=0.04$ ) and smell and taste disorder (2.3\% vs $1.8 \%$; aOR 1.56 ; $95 \%$ CI 1.05 to $2.30 ; \mathrm{p}=0.03)$.

\section{Sensitivity analysis}

Our findings were largely unaffected by excluding respondents living in Tokyo (online supplemental table A1) and using unweighted regression models (online supplemental table A2). The results of the analysis excluding individuals who avoided travels in the past month showed higher incidence rates of sore throat and cough among subsidy programme participants compared with nonparticipants (online supplemental table A3). However, we found no evidence that the incidence of the other three symptoms differed between these two groups. The result of the stratified analyses by age showed that the higher incidence rates of COVID-19 like symptoms were more salient among young respondents (online supplemental table A4). For example, among respondents aged 15-64 years, the adjusted incidence rate of smell and 
Table 1 Sociodemographic and health-related characteristics of respondents by participation in the subsidy programme for domestic travel

\begin{tabular}{|c|c|c|c|c|c|}
\hline Characteristics & & Total ( $\mathrm{N}=\mathbf{2 5 4 8 2 )}$ & $\begin{array}{l}\text { Participants } \\
(\mathrm{N}=3289)\end{array}$ & $\begin{array}{l}\text { Non-participants } \\
(\mathrm{N}=22193)\end{array}$ & $P$ value \\
\hline Female & & $12809(50.3)$ & $1534(46.6)$ & $11275(50.8)$ & 0.29 \\
\hline Age, mean (SD), year & & $48.8(17.4)$ & $45.0(17.9)$ & $49.4(17.3)$ & 0.02 \\
\hline \multirow[t]{2}{*}{ Academic attainment } & College or higher & $12701(49.8)$ & $1973(60.0)$ & $10728(48.3)$ & $<0.001$ \\
\hline & High school or lower & $12781(50.2)$ & $1316(40.0)$ & $11465(51.7)$ & \\
\hline \multirow[t]{4}{*}{ Income level } & Lower & $7336(28.8)$ & $867(26.4)$ & $6469(29.1)$ & $<0.001$ \\
\hline & Intermediate & $6817(26.8)$ & $804(24.4)$ & $6013(27.1)$ & \\
\hline & Higher & $5733(22.5)$ & $1144(34.8)$ & $4589(20.7)$ & \\
\hline & Not answered & $5595(22.0)$ & $474(14.4)$ & $5121(23.1)$ & \\
\hline \multirow[t]{5}{*}{ Household size } & 1 & 4117 (16.2) & 665 (20.2) & $3452(15.6)$ & 0.43 \\
\hline & 2 & $8574(33.7)$ & $1091(33.2)$ & $7482(33.7)$ & \\
\hline & 3 & $5927(23.3)$ & 766 (23.3) & $5160(23.3)$ & \\
\hline & 4 & $4352(17.1)$ & $499(15.2)$ & $3853(17.4)$ & \\
\hline & $5+$ & $2513(9.9)$ & $268(8.1)$ & $2245(10.1)$ & \\
\hline \multirow[t]{4}{*}{ Marital status } & Married & $16100(63.2)$ & $2025(61.6)$ & $14075(63.4)$ & 0.20 \\
\hline & Never married & $6046(23.7)$ & 707 (21.5) & $5339(24.1)$ & \\
\hline & Widowed & $1949(7.7)$ & $427(13.0)$ & $1522(6.9)$ & \\
\hline & Separated & $1387(5.4)$ & $131(4.0)$ & $1256(5.7)$ & \\
\hline \multirow[t]{4}{*}{ Employment } & Employer & $1007(4.0)$ & $262(8.0)$ & 746 (3.4) & 0.10 \\
\hline & Self-employed & $2008(7.9)$ & $305(9.3)$ & $1703(7.7)$ & \\
\hline & Employee & $12745(50.0)$ & $1725(52.4)$ & $11020(49.7)$ & \\
\hline & Unemployed & $9722(38.2)$ & 998 (30.3) & 8724 (39.3) & \\
\hline $\begin{array}{l}\text { Lay-off or unemployment } \\
\text { benefits }\end{array}$ & & $937(3.7)$ & $292(8.9)$ & $645(2.9)$ & 0.02 \\
\hline \multirow[t]{3}{*}{ Smoking status } & Never & $12959(50.9)$ & $1531(46.5)$ & $11429(51.5)$ & 0.47 \\
\hline & Ever & $1638(30.0)$ & $1108(33.7)$ & $6530(29.4)$ & \\
\hline & Current & 4885 (19.2) & 651 (19.8) & $4234(19.1)$ & \\
\hline Walking disability & & $3543(13.9)$ & $644(19.6)$ & $2900(13.1)$ & 0.18 \\
\hline \multirow[t]{8}{*}{ Comorbidities } & Overweight & $5185(20.4)$ & $884(26.9)$ & 4301 (19.4) & 0.04 \\
\hline & Hypertension & $6963(27.3)$ & $1071(32.6)$ & $5891(26.5)$ & 0.17 \\
\hline & Diabetes & $2711(10.6)$ & $515(15.7)$ & $2196(9.9)$ & 0.16 \\
\hline & Asthma & $3573(14.0)$ & $647(19.7)$ & 2926 (13.2) & 0.11 \\
\hline & Coronary disease & $1686(6.6)$ & $401(12.2)$ & $1285(5.8)$ & 0.09 \\
\hline & Stroke & $1288(5.1)$ & $352(10.7)$ & $936(4.2)$ & 0.07 \\
\hline & COPD & $1103(4.3)$ & $338(10.3)$ & $766(3.5)$ & 0.05 \\
\hline & Cancer & $2185(8.6)$ & $374(11.4)$ & $1811(8.2)$ & 0.38 \\
\hline
\end{tabular}

The analyses were weighted to account for selection in an internet survey. Because of weighting, the sum of participants and non-participants did not necessarily equal the number of total respondents. The numbers are no. (\%), except for age. $\mathrm{P}$ values are calculated using an adjusted Wald test for age and $\chi^{2}$ tests for other categorical variables. The analyses of this table were for the purpose of simple description and did not account for multiple comparisons in the presentation of the $p$ values. Comorbidities of hypertension, diabetes, asthma, coronary heart disease, stroke, COPD and cancer was defined as having a medical history of these conditions.

COPD, chronic obstructive pulmonary disease.;

taste disorder was higher for subsidy programme participants compared with younger non-participants, whereas the incidence rates did not differ between participants and non-participants among those aged $65-79$ years $(p$ for interaction=0.04). We found no systemic difference in patterns regarding the association between subsidy programme participation and COVID-19 like symptoms for the stratified analyses by the presence of comorbidity 
Table 2 Preventive measures and fear against the COVID-19 infection of respondents by participation in the subsidy programme for domestic travel

\begin{tabular}{|c|c|c|c|c|}
\hline Characteristics & Total (N=25482) & Participants ( $\mathrm{N}=3289$ ) & Non-participants $(\mathrm{N}=22193)$ & $P$ value \\
\hline \multicolumn{5}{|l|}{ Preventive measures } \\
\hline \multicolumn{5}{|l|}{ Personal preventive actions } \\
\hline Social distancing & $21359(83.8)$ & $2776(84.4)$ & $18582(83.7)$ & 0.85 \\
\hline Wearing masks & $24018(94.3)$ & 3074 (93.5) & $20944(94.4)$ & 0.80 \\
\hline Avoiding closed spaces & $20728(81.3)$ & 2574 (78.3) & $18154(81.8)$ & 0.43 \\
\hline Avoiding crowded spaces & $22949(90.1)$ & 3028 (92.1) & $19921(89.8)$ & 0.08 \\
\hline Avoiding close contact settings & $20152(79.1)$ & $2381(72.4)$ & $17771(80.1)$ & 0.09 \\
\hline Handwashing & $22191(87.1)$ & 2956 (89.9) & $19235(86.7)$ & 0.02 \\
\hline Avoiding touching face & $19591(76.9)$ & 2511 (76.3) & $17080(77.0)$ & 0.87 \\
\hline Respiratory hygiene & $22037(86.5)$ & $2856(86.8)$ & $19182(86.4)$ & 0.92 \\
\hline Surface disinfection & $13340(52.4)$ & $1625(49.4)$ & $11715(52.8)$ & 0.40 \\
\hline \multicolumn{5}{|l|}{ High-risk behaviour patterns } \\
\hline Visiting restaurants & $6674(26.3)$ & $1305(39.7)$ & $5369(24.2)$ & $<0.001$ \\
\hline Visiting bars/nightclubs & $4185(16.4)$ & $1013(30.8)$ & $3172(14.3)$ & $<0.001$ \\
\hline Visiting karaoke bars & $2465(9.7)$ & $630(19.2)$ & $1836(8.3)$ & 0.01 \\
\hline Visiting fitness clubs & $2712(10.6)$ & $736(22.4)$ & $1976(8.9)$ & $<0.001$ \\
\hline Visiting brothels & $1885(7.4)$ & $438(13.3)$ & $1447(6.5)$ & 0.08 \\
\hline \multicolumn{5}{|l|}{ Proxies of other preventive measures } \\
\hline Use of contact-tracing app & $4331(17.0)$ & $996(30.3)$ & $3336(15.0)$ & $<0.001$ \\
\hline Support for stay-at-home requests & $19825(77.8)$ & $2668(81.1)$ & $17158(77.3)$ & 0.32 \\
\hline Influenza vaccine in the last season & $8791(34.5)$ & $1403(42.7)$ & $7389(33.3)$ & 0.03 \\
\hline \multicolumn{5}{|l|}{ Fear against the COVID-19 infection } \\
\hline Not afraid at all & $1641(6.4)$ & $217(6.6)$ & $1424(6.4)$ & 0.71 \\
\hline Not afraid & $1910(7.5)$ & $317(9.6)$ & $1592(7.2)$ & \\
\hline Neutral & $5793(22.7)$ & $786(23.9)$ & 5007 (22.6) & \\
\hline Somewhat afraid & $9423(37.0)$ & $1122(34.1)$ & $8302(37.4)$ & \\
\hline Very afraid & $6715(26.4)$ & $847(25.8)$ & $5868(26.4)$ & \\
\hline
\end{tabular}

The analyses were weighted to account for selection in an internet survey. Because of weighting, the sum of participants and non-participants did not necessarily equal the number of total respondents. The numbers are no. (\%). Personal preventive actions included nine personal protective measures recommended by the WHO. High-risk behaviour patterns included five risky behaviours for COVID-19 during the state of emergency. The fear against the COVID-19 infection was measured on a five-point scale of 'not afraid at all ( $0 \%$ if I were to rate the level of fear between $0 \%$ and 100\%)', 'not afraid (25\%)', 'neutral (50\%)', 'somewhat afraid (75\%)' and 'very afraid (100\%)' to the question 'Are you afraid of the COVID-19 infection?'. P values are calculated $\mathrm{X}^{2}$ test. The analyses of this table were for the purpose of simple description and did not account for multiple comparisons in the presentation of the $p$ values.

and gender (online supplemental tables A5 and A6). There were no consistent regional variations in the relationships between the subsidy programme participation and COVID-19 like symptoms (online supplemental table A7).

\section{DISCUSSION}

Using the data from a large cross-sectional internet survey that included more than 25000 adults in Japan, we found that individuals who participated in the government's subsidy programme for domestic travel experienced a higher incidence of COVID-19 like symptoms compared with those who did not participate. This association was also observed for the incidence of smell and taste disorder, which is a highly specific symptom of the COVID-19 infection. ${ }^{19} 33$ These findings were qualitatively unaffected by additional adjustments for preventive measures and fear against the COVID-19 infection, indicating that the systemic differences in participants and non-participants in the subsidy programme regarding risky behaviours do not explain the observed associations between the subsidy programme and the higher incidence of COVID-19 like symptoms. This increased incidence of COVID-19 like symptoms was salient among individuals aged $<65$ years, but not for those aged $\geq 65$ years, suggesting that the nonelderly generation may be contributing to the spread 


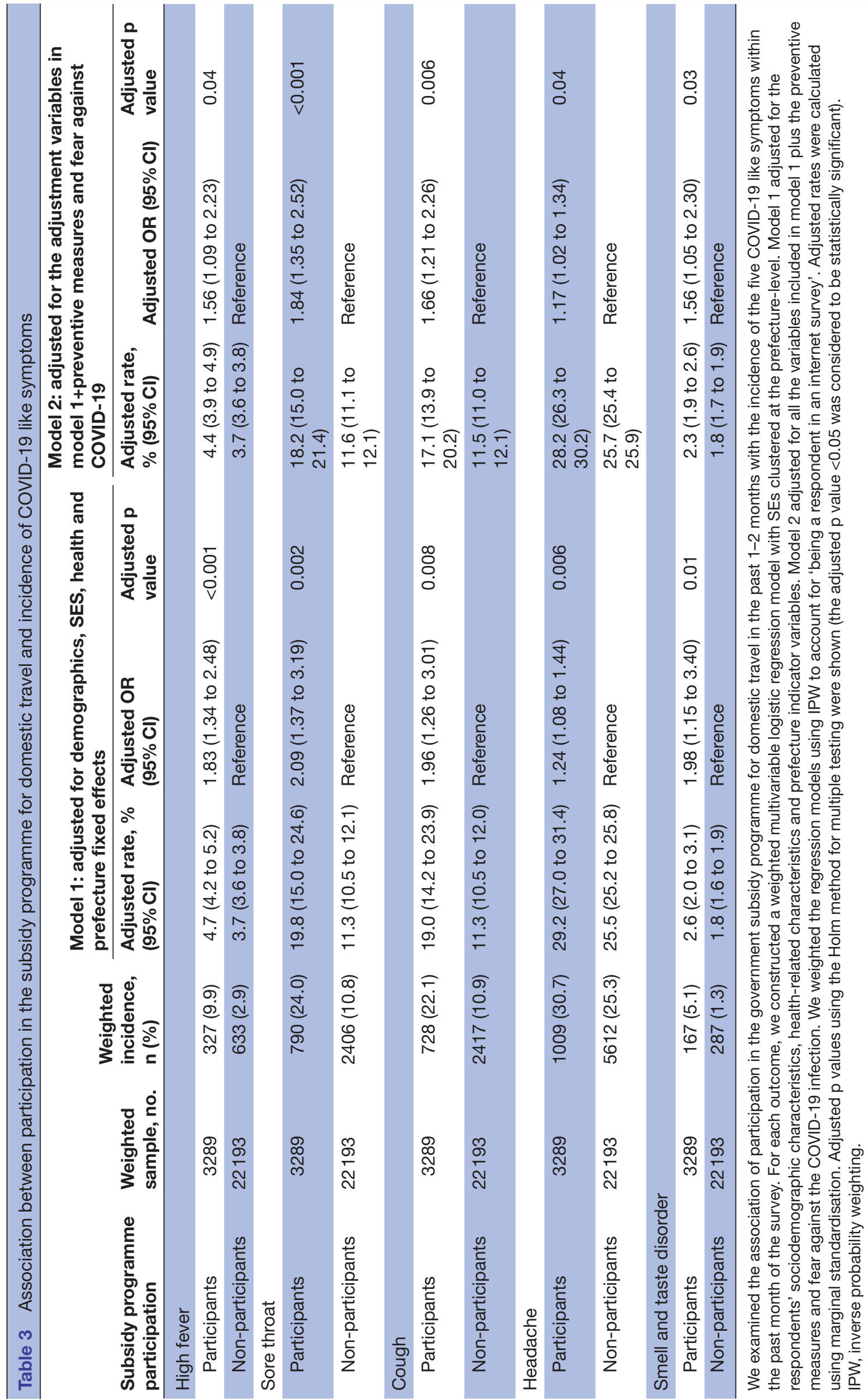

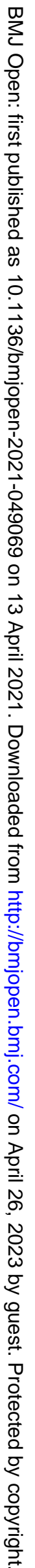


of COVID-19 infection associated with this programme. Given that the Japanese government is debating the implementation of this subsidy programme due to concerns about increased risks of COVID-19 infections and that other countries are actively considering similar policies to stimulate their economies ${ }^{6-10}$ our findings should be informative for designing policies that could increase economic activities without exacerbating the COVID-19 pandemic.

There are several mechanisms through which participation in this subsidy programme for domestic travel was associated with a higher incidence of COVID-19 like symptoms. First, increased contact with people while dining and sightseeing at the destination in travelling may have led to a higher risk of incidence of COVID-19 (causal effect). This explanation is supported by a recent genome epidemiological study of SARS-CoV-2 in Japan that found the possibility that the COVID-19 clusters in the Tokyo metropolitan areas might have spread throughout Japan after lifting movement restrictions. ${ }^{34}$ This hypothesis is supported by a study from the USA that found the volume of domestic airline travel around the Thanksgiving holiday was positively associated with the spread of seasonal influenza. ${ }^{35}$ Second, subsidy programme participants might have been more likely to engage in behaviours that placed them at greater risk of contracting COVID-19 than non-participants (selection effect). However, the fact that our results remained statistically significant after additional adjustment for preventive behaviours suggests that this explanation alone may be insufficient to explain the observed relationship between participation in this programme and a higher likelihood of experiencing COVID-19 like symptoms. Furthermore, even if the findings were to be explained by this selection effect, our findings indicate that the subsidy programme may be incentivising those with higher risks of COVID-19 transmission to travel across the nation, leading to the expansion of the outbreaks across regions (eg, from the urban to the rural tourist spots). A better policy may be to directly provide financial assistance to affected sectors (eg, travel industries) and encourage all individuals to stay at home until vaccinated.

Analysis after excluding individuals who avoided travels in the past month also showed that programme participants were more likely to experience some COVID-19 like symptoms. This finding suggests the possibility that participants and non-participants may have different behavioural patterns in travelling, including the destination, the frequency and duration of travel (more often or longer for participants) and the method of travel (participants might be more likely to use public transportation (vs private vehicle) because the programme subsidised the expense of public transportation for travel). Also, programme participants might have more opportunities to allocate the money saved by discounts to activities such as eating and shopping, which might increase the rate of infection.

\section{Strengths and limitations of this study}

The main strengths of this study were its use of large-sized nationwide data and a unique setting in which a large nationwide government subsidy for travel was initiated before the spread of COVID-19 was contained.

Our study has limitations. First, as with any observational study, we could not fully account for unmeasured confounders, and our study was unable to identify the exact mechanisms of the association between subsidy programme participation and increased incidence rates of COVID-19 like symptoms. Second, given the crosssectional design of our study, we could not identify the temporal relationship between the subsidy programme and the incidence of COVID-19 like symptoms. Instead of the government subsidy causing infections of COVID19 , it was also possible that individuals who experienced COVID-19 like symptoms were more likely to use the programme and travel domestically. However, this explanation may be unlikely given that travel agents and hotels have introduced strict protocols to ensure that no one with COVID-19 like symptoms uses their services. Also, individuals who spread the virus are likely to face criticism and stigma in Japan, which incentivises people with suspected symptoms to stay at home. ${ }^{36}$ Third, it is likely that some individuals who reported five COVID-19 like symptoms had illnesses that were not COVID-19, as we were unable to collect data on confirmed diagnoses of COVID-19 infection (eg, diagnoses using the PCR test). However, smell and taste disorders, one of the outcomes we used, are known to be highly specific (90\% specificity) to a COVID-19 diagnosis, ${ }^{19} 33$ suggesting that these symptoms would be good proxies for the incidence of COVID-19. Moreover, symptom-based measures would supplement the PCR test based surveillance to inform a populationlevel picture of COVID-19 infection ${ }^{20}{ }^{21}$ because PCR testing underestimates the true number of infections (not everyone with symptoms indicative of COVID-19 is tested). Nevertheless, prospective studies that investigate the association between the participation in the subsidy programme for domestic travel and COVID-19 incidence (identified by PCR test or administrative data) warrant. Fourth, our findings may be affected by the possibility that individuals who presented with COVID-19 like symptoms might recall and report using the subsidy programme for domestic travel (as the cause of their symptoms) compared with individuals without such symptoms (recall bias). However, the questions on the programme participation and COVID-19 like symptoms were located in a remote part of the questionnaire among the more than 100 other questions asked (and therefore certainly considered irrelevant to the respondents), and this recall bias problem would be minimal. Conversely, it is also possible that those participating in the subsidy programme may under-report COVID-19 like symptoms. However, if this is the case, this would bias our estimates towards the null, and the true difference in COVID-19-like symptoms between the participants and non-participants of the subsidy programme would be larger than what we 
have estimated. Fifth, the information on how many times the respondents travelled was unavailable, and we could not distinguish one-time travellers from frequent travellers. Finally, we used the weighted analyses to address the issue that the participants were recruited from the survey panel of registered individuals in the internet research agency (to minimising the difference in demographics, SES and health-related characteristics between respondents of the current internet survey and the nationally representative sample). However, it is still possible that individuals included in our analyses differed from the general population in unmeasurable ways, and therefore, our findings may not be generalisable to other populations, such as the population with limited access to and literacy about the internet.

\section{Comparison with other studies}

Our findings were consistent with those from a limited set of empirical studies on the association between domestic travel and the COVID-19 spread. Studies in China at the early stage of the COVID-19 epidemic found a positive association between domestic passenger travel volume from Wuhan City and the confirmed COVID-19 cases within the other 10 cities in China. ${ }^{38}$ Another study showed a preventive effect of a travel ban from Wuhan against the COVID-19 spread. $^{39}$ A recent study in 149 countries found that a combination of stay-at-home regulations and restrictions on movements within a country reduce the COVID-19 spread, but this study did not examine an independent effect of domestic travels. ${ }^{4}$ To our knowledge, there have been no studies that have investigated the impact of government subsidies for travel, which is a unique economic policy introduced in Japan, on the spread of COVID-19 infections. Anzai and Nishiura ${ }^{40}$ have recently reported an increase in the number of travel-related COVID-19 confirmed cases in the month just after the introduction of this programme than in the month before. However, their study found that non-travel-related cases also increased to the same extent, and the association between the subsidy programme and the spread of COVID-19 was unclear.

\section{CONCLUSION}

Using a large-scale, concurrent, nationwide internet survey in Japan, we found that participants in the government subsidy programme for domestic travel in Japan had higher incidence rates of COVID-19 like symptoms compared with non-participants. Our findings suggest that the implementation of the subsidy programme for domestic travel might have contributed to increased cases of COVID-19 infections. In the midst of an economic recession due to the COVID-19 pandemic, economic stimulus policies should take the form of directly subsidising financial loss of affected sectors or incentivising economic activities that do not involve increase physical interactions, rather than incentivising individuals to travel more or use restaurants.
Author affiliations

${ }^{1}$ Department of Public Health, Graduate School of Medicine, The University of Tokyo, Bunkyo-ku, Japan

${ }^{2}$ Cancer Control Center, Osaka International Cancer Institute, Osaka, Osaka, Japan ${ }^{3}$ Faculty of Health and Social Services, Kanagawa University of Human Services, Yokosuka, Kanagawa, Japan

${ }^{4}$ Division of General Internal Medicine and Health Services Research, UCLA David Geffen School of Medicine, Los Angeles, California, USA

${ }^{5}$ Department of Health Policy and Management, UCLA Fielding School of Public Health, Los Angeles, California, USA

Twitter Atsushi Miyawaki @AMiyawaki38 and Yusuke Tsugawa @ytsugawa1

Acknowledgements The data of the Japan "COVID-19 and Society" Internet Survey (JACSIS) study were collected with the support of JSPS KAKENHI Grants (grant number 18H03062; 17H03589; 19K10671; 19K19439; 19K10446; and 18H03107), University of Tsukuba Research Support Program (grant number is not applicable) and Health Labour Sciences Research Grants (19FA1005). We would like to thank Drs Kota Katanoda, Keisuke Kuwahara, Kanami Tsuno, Kenji Takeuchi, Hiroshi Murayama, Ai Hori and Isao Muraki for the administrative support related to the collection of the survey data of the JACSIS study.

Contributors AM conceptualisation, data curation, formal analysis, investigation, methodology, resources, software, visualisation and writing - original draft. TT: data curation, funding acquisition, investigation, methodology, project administration, resources, validation and writing - review and editing. YTo: data curation, funding acquisition, investigation, methodology, resources, validation and writing - review and editing. YTs: conceptualisation, investigation, methodology, resources, software, supervision, visualisation, writing - original draft and writing - review and editing.

Funding This work was funded by the Japan Society for the Promotion of Science (JSPS) KAKENHI Grants (18H03062 to TT). AM was supported by JSPS KAKENHI Grants (20K18956) and the Social Science Research Council (grant number is not applicable) unrelated to this study. YT was supported by the National Institutes of Health (NIH)/National Institute on Minority Health and Health Disparities (NIMHD) Grant R01MD013913 and NIH/National Institute on Aging (NIA) Grant R01AG068633 for other work not related to this study. The funders/sponsors were not involved with the collection, management, analysis or interpretation of the data; preparation, review or approval of the manuscript; or the decision to submit the manuscript for publication. All authors had full access to all the data in the study and had the final responsibility for the decision to submit the paper.

Competing interests None declared.

Patient consent for publication Not required.

Ethics approval This study was approved by the Institutional Review Board of the Osaka International Cancer Institute (No. 20084).

Provenance and peer review Not commissioned; externally peer reviewed.

Data availability statement Data are available on reasonable request. The JACSIS study dataset is available on request to the corresponding author.

Supplemental material This content has been supplied by the author(s). It has not been vetted by BMJ Publishing Group Limited (BMJ) and may not have been peer-reviewed. Any opinions or recommendations discussed are solely those of the author(s) and are not endorsed by BMJ. BMJ disclaims all liability and responsibility arising from any reliance placed on the content. Where the content includes any translated material, BMJ does not warrant the accuracy and reliability of the translations (including but not limited to local regulations, clinical guidelines, terminology, drug names and drug dosages), and is not responsible for any error and/or omissions arising from translation and adaptation or otherwise.

Open access This is an open access article distributed in accordance with the Creative Commons Attribution Non Commercial (CC BY-NC 4.0) license, which permits others to distribute, remix, adapt, build upon this work non-commercially, and license their derivative works on different terms, provided the original work is properly cited, appropriate credit is given, any changes made indicated, and the use is non-commercial. See: http://creativecommons.org/licenses/by-nc/4.0/.

\section{ORCID iDs}

Atsushi Miyawaki http://orcid.org/0000-0001-6126-1464

Takahiro Tabuchi http://orcid.org/0000-0002-1050-3125

Yusuke Tsugawa http://orcid.org/0000-0002-1937-4833 


\section{REFERENCES}

1 World Health Organization. WHO coronavirus disease (COVID-19) dashboard, 2020. Available: https://covid19.who.int

2 Flaxman S, Mishra S, Gandy A, et al. Estimating the effects of non-pharmaceutical interventions on COVID-19 in Europe. Nature 2020;584:257-61.

3 Davies NG, Kucharski AJ, Eggo RM, et al. Effects of nonpharmaceutical interventions on COVID-19 cases, deaths, and demand for hospital services in the UK: a modelling study. Lancet Public Health 2020;5:e375-85.

4 Islam N, Sharp SJ, Chowell G, et al. Physical distancing interventions and incidence of coronavirus disease 2019: natural experiment in 149 countries. BMJ 2020;370:m2743.

5 Vardavas R, Strong A, Bouey J. The health and economic impacts of nonpharmaceutical interventions to address COVID-19: a decision support tool for state and local policymakers. RAND Corporation 2020.

6 Jones D. These destinations will basically pay you to come visit during the pandemic. Washington post, 2020. Available: https:// www.washingtonpost.com/travel/2020/05/29/these-destinationswill-basically-pay-you-come-visit-during-pandemic/ [Accessed 1 Jan 2021].

7 McGowan M. NSW government considers restaurant and CAFE vouchers to boost covid-hit industry New South Wales, 2020. Available: https://www.theguardian.com/australia-news/2020/nov/06/ nsw-government-considers-restaurant-and-cafe-vouchers-to-boostcovid-hit-industry [Accessed 1 Jan 2021].

8 MacCurry J. Japan's GoTo domestic tourism push stalls amid fears of Covid-19 'disaster' coronavirus, 2020. Available: https://www. theguardian.com/world/2020/jul/22/japans-goto-domestic-tourismpush-stalls-amid-fears-of-covid-19-disaster [Accessed 1 Jan 2021].

9 United Kingodom Government. Get a discount with the eat out to help out scheme, 2020. Available: https://www.gov.uk/guidance/geta-discount-with-the-eat-out-to-help-out-scheme [Accessed 1 Jan 2021].

10 Yonhap News Agency. Gov't resumes discount coupon program for travel, dining sectors, 2020. Available: http://m.koreatimes.co.kr/ pages/article.asp?newsldx=298521 [Accessed 2 Jan 2021].

11 Fetzer T. Subsidizing the spread of COVID19: evidence from the UK's eat-out-to-help-out scheme, 2020. Available: https://warwick.ac.uk/ fac/soc/economics/research/centres/cage/manage/publications/wp. 517.2020.pdf [Accessed 1 Jan 2021].

12 Japan Tourism Agency, Ministry of Land, Infrastructure, Transport and Tourism. Usage on the 'go-to' domestic travel recovery initiative: press, 2020. Available: https://www.mlit.go.jp/kankocho/news06 000484.html [Accessed 1 Jan 2021].

13 Takahashi R. Government revises go to travel campaign amid nationwide surge, 2020. Available: https://www.japantimes.co.jp/ news/2020/11/21/national/go-to-travel-coronavirus-surge/ [Accessed 2 Jan 2021].

14 The Japan Times. Japan travel campaign to stay suspended after emergency lifted, 2021. Available: https://www.japantimes.co.jp/ news/2021/02/28/national/covid-19-japan-health-travel-go-to-travel/ [Accessed 23 Mar 2021].

15 Rakuten Insight, Inc. About us: Rakuten insight, 2020. Available: https://insight.rakuten.co.jp/en/aboutus.html [Accessed 1 Jan 2021].

16 Tabuchi T, Kiyohara K, Hoshino T, et al. Awareness and use of electronic cigarettes and heat-not-burn tobacco products in Japan. Addiction 2016;111:706-13.

17 Tabuchi T, Shinozaki T, Kunugita N, et al. Study profile: the Japan "society and new tobacco" internet survey (JASTIS): a longitudinal internet cohort study of heat-not-burn tobacco products, electronic cigarettes, and conventional tobacco products in Japan. J Epidemiol 2019;29:444-50.

18 Okubo R, Yoshioka T, Nakaya T, et al. Urbanization level and neighborhood deprivation, not COVID-19 case numbers by residence area, are associated with severe psychological distress and newonset suicidal ideation during the COVID-19 pandemic. J Affect Disord 2021;287:89-95.
19 Struyf T, Deeks JJ, Dinnes J, et al. Signs and symptoms to determine if a patient presenting in primary care or hospital outpatient settings has COVID-19. Cochrane Database Syst Rev 2021;2:CD013665.

20 UK Research and Innovation. Using symptom-based measures for tracking COVID-19, 2020. Available: https://coronavirusexplained. ukri.org/en/article/und0005/\#ref2 [Accessed 2 Jan 2021].

21 Nomura S, Yoneoka D, Shi S. An assessment of self-reported COVID-19 related symptoms of 227898 users of a social networking service in Japan: has the regional risk changed after the declaration of the state of emergency? Lancet Regional Health - Western Pacific 2020;1.

22 Giannouchos TV, Sussman RA, Mier JM. Characteristics and risk factors for COVID-19 diagnosis and adverse outcomes in Mexico: an analysis of 89,756 laboratory-confirmed COVID-19 cases. Eur Respir $J 2020$.

23 Wadhera RK, Wadhera P, Gaba P, et al. Variation in COVID-19 hospitalizations and deaths across New York City boroughs. JAMA 2020;323:2192-5.

24 World Health Organization. Coronavirus disease (COVID-19) advice for the public, 2020. Available: https://www.who.int/emergencies/ diseases/novel-coronavirus-2019/advice-for-public [Accessed 1 Jan 2021].

25 Furuse Y, Sando E, Tsuchiya N, et al. Clusters of coronavirus disease in communities, Japan, January-April 2020. Emerg Infect Dis 2020;26:2176-9.

26 Ministry of Health Labour and Welfare. COCOA - COVID-19 contactconfirming application, 2020. Available: https://www.mhlw.go.jp/stf/ seisakunitsuite/bunya/cocoa 00138.html [Accessed 1 Jan 2021].

27 Schonlau M, van Soest A, Kapteyn A, et al. Selection bias in web surveys and the use of propensity scores. Sociol Methods Res 2009;37:291-318.

28 Ministry of Health, Labour and Welfare. Comprehensive survey of living conditions, 2019. Available: https://www.mhlw.go.jp/toukei/list/ 20-21.html [Accessed 1 Jan 2021].

29 Shibuya K, Hashimoto H, Yano E. Individual income, income distribution, and self rated health in Japan: cross sectional analysis of nationally representative sample. BMJ 2002;324:16.

30 Williams R. Using the margins command to estimate and interpret adjusted predictions and marginal effects. Stata J 2012;12:308-31.

31 Holm S. A simple sequentially rejective multiple test procedure. Scand J Stat 1979;6:65-70

32 Chan AOO, Jim MH, Lam KF, et al. Prevalence of colorectal neoplasm among patients with newly diagnosed coronary artery disease. JAMA 2007;298:1412-9.

33 Bénézit $F$, Le Turnier $P$, Declerck $C$, et al. Utility of hyposmia and hypogeusia for the diagnosis of COVID-19. Lancet Infect Dis 2020;20:1014-5.

34 National Insitutute of Infectious Diseases. A genome epidemiological study of SARS-CoV-2 in Japan as of July 16, 2020, 2020. Available: https://www.niid.go.jp/niid/images/research info/genome-2020 SARS-CoV-MolecularEpidemiology_2.pdf [Accessed 1 Jan 2021]

35 Brownstein JS, Wolfe CJ, Mandl KD. Empirical evidence for the effect of airline travel on inter-regional influenza spread in the United States. PLoS Med 2006;3:e401.

36 Osaki T. Japan's 'virus vigilantes' take on rule-breakers and invaders 2020. Available: https://www.japantimes.co.jp/news/2020/05/13/ national/coronavirus-vigilantes-japan/ [Accessed 1 Jan 2021].

37 Kraemer MUG, Yang C-H, Gutierrez B, et al. The effect of human mobility and control measures on the COVID-19 epidemic in China. Science 2020;368:493-7.

38 Zhao S, Zhuang Z, Cao P, et al. Quantifying the association between domestic travel and the exportation of novel coronavirus (2019nCoV) cases from Wuhan, China in 2020: a correlational analysis. J Travel Med 2020;27:taaa022.

39 Chinazzi M, Davis JT, Ajelli M, et al. The effect of travel restrictions on the spread of the 2019 novel coronavirus (COVID-19) outbreak. Science 2020;368:395-400.

40 Anzai A, Nishiura H. "Go to travel" campaign and travel-associated coronavirus disease 2019 cases: a descriptive analysis, July-August 2020. J Clin Med 2021;10:398. 